\title{
Ecotoxicological effects of carbon nanotubes and cellulose nanofibers in Chlorella vulgaris
}

\author{
Michele M Pereira ${ }^{1}$, Ludovic Mouton ${ }^{2}$, Claude Yéprémian ${ }^{3}$, Alain Couté ${ }^{3}$, Joanne Lo ${ }^{4}$, José M Marconcini ${ }^{5}$, \\ Luiz O Ladeira ${ }^{6}$, Nádia RB Raposo ${ }^{1}$, Humberto M Brandão ${ }^{7}$ and Roberta Brayner ${ }^{2^{*}}$
}

\begin{abstract}
Background: MWCNT and CNF are interesting NPs that possess great potential for applications in various fields such as water treatment, reinforcement materials and medical devices. However, the rapid dissemination of NPs can impact the environment and in the human health. Thus, the aim of this study was to evaluate the MWCNT and cotton CNF toxicological effects on freshwater green microalgae Chlorella vulgaris.

Results: Exposure to MWCNT and cotton CNF led to reductions on algal growth and cell viability. NP exposure induced reactive oxygen species (ROS) production and a decreased of intracellular ATP levels. Addition of NPs further induced ultrastructural cell damage. MWCNTs penetrate the cell membrane and individual MWCNTs are seen in the cytoplasm while no evidence of cotton CNFs was found inside the cells. Cellular uptake of MWCNT was observed in algae cells cultured in BB medium, but cells cultured in Seine river water did not internalize MWCNTs.

Conclusions: Under the conditions tested, such results confirmed that exposure to MWCNTs and to cotton CNFs affects cell viability and algal growth.
\end{abstract}

Keywords: Nanoparticle, Uptake, Nanotoxicity, Microalgae, Bioindicator

\section{Background}

In recent years, many newly engineered nanomaterials are being developed due to the fast-growing area of nanotechnology. CNT and CNF are NPs that have received considerable attention. CNTs have unique characteristics, such as large contact surface, stability, flexibility, stiffness, strength, thermal and electrical conductivity. CNF has emerged as an attractive nanomaterial due to their hydrophilicity, flexibility, mechanical strength, broad chemical-modifying capacity, biodegradability aspect and low cost. Thus, CNTs and CNFs are noteworthy NPs, which encompass a number of potential applications, being used in water treatment, cosmetics, as well as reinforcement materials, biosensors and medical equipment [1-4].

Nevertheless, the rapid dissemination of NPs can cause an impact on the environment and on human health. So far, however, most nanomaterial-based publications are focused on the synthesis and development of new nanomaterials, and few studies have focused on NPs' ecotoxicological

\footnotetext{
* Correspondence: roberta.brayner@univ-paris-diderot.fr

${ }^{2}$ Interfaces, Traitements, Organisation et Dynamique des Systèmes (ITODYS),

University of Paris Diderot, Sorbonne Paris Cité, 7086 Paris, France

Full list of author information is available at the end of the article
}

impact. Some works have investigated the impact of CNTs on algal ecosystems [5-7]. Thus, at present, the knowledge on the ecotoxicological effects of CNTs is still limited, despite the large number of ongoing studies. Notably, in the case of cotton CNFs, no work, until now, has studied the potential cytotoxicity to microalgae cells and only one study suggested that cotton CNFs were genotoxic in plant cells [8]. Therefore, the ecotoxicological impact of CNTs and CNFs has to be determined. For this purpose, Chlorella vulgaris is a valuable bioindicator of potentially toxic elements and due to the ecological position of this organism at the base of the aquatic food chain and oxygen production. The objective of the current paper is to elucidate whether MWCNTs and cotton CNFs are toxic to $C$. vulgaris in BB medium or in natural water (Seine River).

This work provides a direct comparison of the impact of MWCNTs and cotton CNFs to C. vulgaris, either in $\mathrm{BB}$ culture medium or in Seine river water. To our knowledge, the interactions between MWCNTs or cotton CNFs and C. vulgaris in different types of growth medium have not been studied. 


\section{Results and discussion}

\section{Characterization of NPs and suspensions}

SEM images of the nanomaterials we used are presented in Figure 1A and B. The XRD patterns in Figure $1 \mathrm{C}$ and $\mathrm{D}$ indicate that both NPs have pure structural characteristics of MWCNT and cotton CNF materials. Before contact with the microorganisms, the ZP of MWCNT and $\mathrm{CNF}$ nanoparticles with varying $\mathrm{pH}$ of the media (BB and Seine river water) was measured after 30 minutes of contact between the nanoparticles and the $\mathrm{pH}$ solutions (Figure 2). The ZPC for MWCNT nanoparticles was observed at $\mathrm{pH} 4.0$ and $\mathrm{pH} 4.8$ for the $\mathrm{BB}$ medium (Figure 2A) and Seine river water solutions (Figure 2B), respectively. For the CNF nanoparticles, the $\mathrm{ZPC}$ is at a $\mathrm{pH}<2$ in both $\mathrm{BB}$ culture medium (Figure $2 \mathrm{C}$ ) and in the Seine river water (Figure 2D).

Both MWCNT and CNF nanoparticles are negatively charged at neutral $\mathrm{pH}$ (7.0). C. vulgaris is also negatively charged at this $\mathrm{pH}$. We expected no interactions between nanoparticles and C. vulgaris. This behavior was observed in Seine river water, on the other hand, the ZP was changed in $\mathrm{BB}$ medium due to the high ionic strength of this medium. CNF nanoparticles are most positively charged than MWCNT. For CNF materials the ZP changed in both media.

These results suggest that there are few cationic sites for adsorption of the negatively charged NPs. It is well known that positively charged NPs have more cellular uptake than negative NPs, due to the attractive electrostatic interactions with the cell membrane. However, anionic NPs bind to the cell surface on the form of clusters because of their repulsive interactions with the large negatively charged domains of the cell surface [9]. In addition, Patil et al. [10] showed the high cellular uptake of negatively charged nanoparticles and suggest that this is related to the non-specific process of NP adsorption at the positively charged sites on the cell-membrane. In fact, cytotoxicity assay and microscopy results showed interactions between NPs and algae cells.

\section{Effect of NPs on algae growth and viability}

The effect of NPs on the viability of $C$. vulgaris was assessed by direct cell counting. Figure 3A shows the toxic effect of NPs on C. vulgaris cultured in BB medium as a function of concentrations and exposure times. After 24 hours of exposure, the cell numbers were changed $(\mathrm{P}<0.001)$. Interestingly, NP exposure led to a decreased in the number of cells, in a non-dose-dependent manner, and for both NPs, the inhibition of algal growth rate occurred at the concentration of $1 \mu \mathrm{g} \mathrm{ml}^{-1}$. Such findings are in agreement with previous studies, showing that the CNTs reduced the algal growth of $C$. vulgaris $[5,7,11]$. Microscopy analyses showed aggregation between NPs and microalgae (Figure 4). Previous work reported that the proximity of algal cells clogged inside CNT agglomerates lead to different growth conditions [12]. Such behavior can disrupt the supply of sufficient nutrients, which is a crucial factor to the microalgae growth [13]. Additionally, Sargent et al. [14] demonstrated disruption in the mitotic spindle by SWCNTs. Thus, in the present study, the growth inhibition caused by these NPs was most likely the result of insufficient illumination and nutrient availability of algal cells in agglomerates of NPs. In Seine river water, a decrease in algal growth was only observed after 24 hours of exposure $\left(100 \mu \mathrm{g} \mathrm{ml}^{-1} \mathrm{MWCNT}\right)(\mathrm{P}=0.022)$ (Figure $\left.3 \mathrm{~B}\right)$. This behavior may be due to the presence of natural polymers in Seine river water such as fulvic and humic acids that can adsorb on the particle surface.

In the present study, the impact of NPs on algae membrane integrity was assessed with the Trypan Blue assay. Exposure of $C$. vulgaris cells to MWCNTs or cotton CNFs led to significant reductions in algal viability, depending on the dosage and exposure time (Figure $3 \mathrm{C}$ and $\mathrm{D}$ ). From the results, it could be seen that MWCNTs in BB medium caused a reduction of cell viability at all concentrations tested $(45.50-69.83 \%$ relative to controls; $\mathrm{P}<0.001)$. However, for cotton CNFs ( 1 and $50 \mu \mathrm{g} \mathrm{ml} \mathrm{m}^{-1}$ ), the toxicity (50.50 and $48.83 \%$, respectively; $\mathrm{P}<0.001$ ) was only observed over 72 hours of exposure (Figure $3 \mathrm{C}$ ).

On the other hand, cells that were incubated in Seine river water during exposure to MWCNTs did not show a decrease in viability from $1 \mu \mathrm{g} \mathrm{ml}^{-1}$ to 72 hours, but at $96 \mathrm{~h}$, a reduction in cell viability to $61.70 \%(\mathrm{P}=0.038)$ was observed, when compared to control $66.56 \%$ (Figure 3D). A particularly drastic decrease in cell viability $(\mathrm{P}<0.001)$ was observed at high concentrations (50 and $100 \mu \mathrm{g} \mathrm{ml}^{-1}$ ) of MWCNTs (55.33\% and 33.95\%, respectively; Figure 3D). Such results are consistent with other CNT cell viability studies, albeit in different cell types $[5,14,15]$.

For cotton CNFs in the Seine river water, all concentrations were toxic, especially after 72 hours of exposure (Figure 3D). Recent reports indicated the toxicity of cotton CNFs on mammalian and plant cells. Clift et al. [16] showed low in vitro cytotoxicity of cotton CNFs in human lung cells. Previous work in our laboratory showed that high concentrations (2000 and $\left.5000 \mu \mathrm{g} \mathrm{ml}^{-1}\right)$ of cotton CNFs cause a decrease in cell viability in bovine fibroblasts Pereira et al. [17]. In particular, cotton CNFs were reported to be genotoxic in plant cells [8]. Our results are in agreement with these previous studies.

\section{Photosynthetic activity}

The photosynthetic activity of $C$. vulgaris after addition of MWCNTs or cotton CNFs was measured using a PAM fluorimeter (Figure 5A and B). For BB medium, 1 and $50 \mu \mathrm{g} \mathrm{ml}^{-1} \mathrm{MWCNTs}$ or $1 \mu \mathrm{g} \mathrm{ml}^{-1}$ cotton CNFs did not influence the photosynthetic activity of $C$. vulgaris after 72 hours exposure $(\mathrm{P}>0.05)$. However, the photosynthetic 


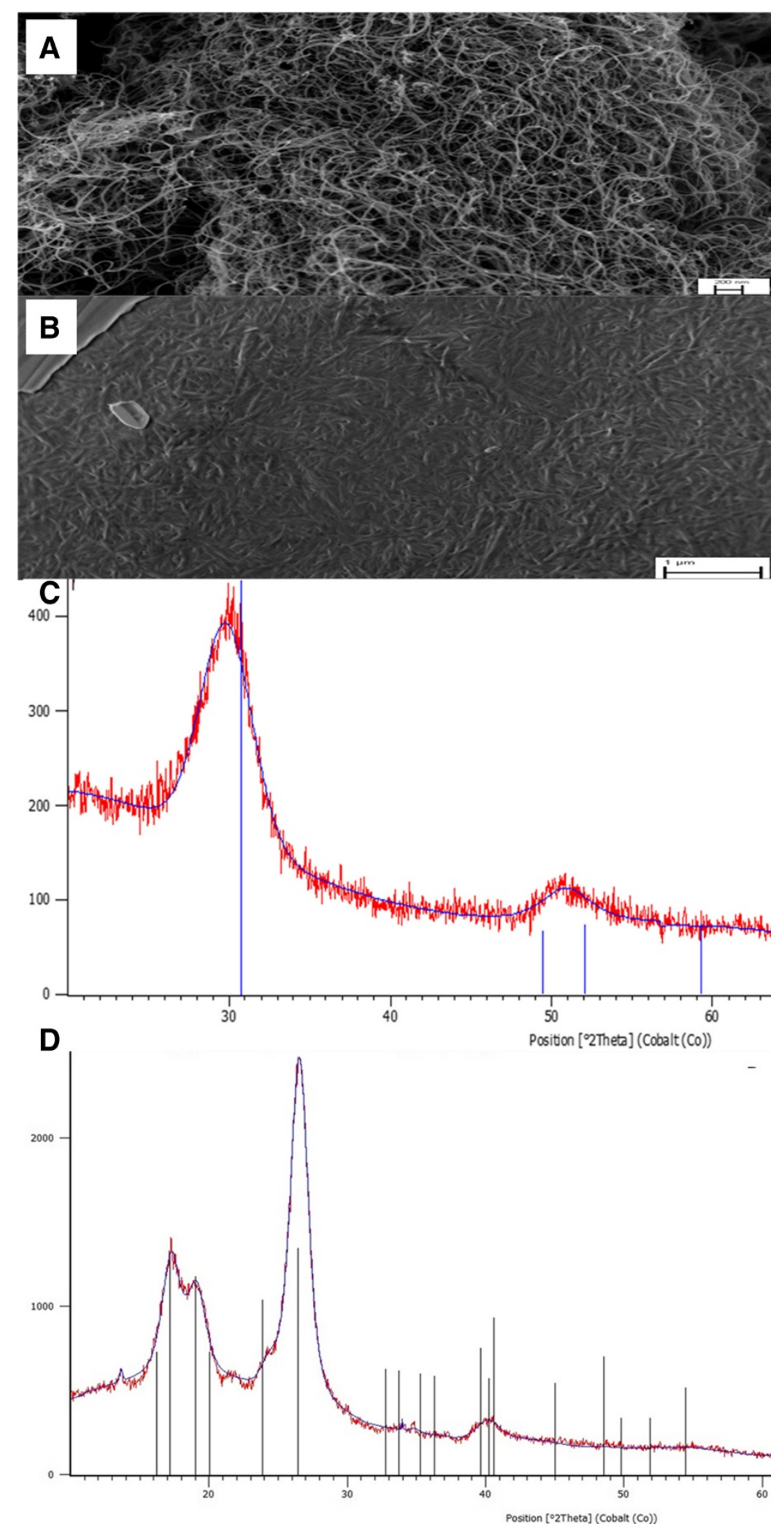

Figure 1 Nanoparticles characterization. SEM images of the Multi-walled carbon nanotubes (MWCNTS) (A) and cotton cellulose nanofibers (CNFs) (B). X-ray diffraction patterns of the MWCNTs (C) and cotton CNFs (D). 

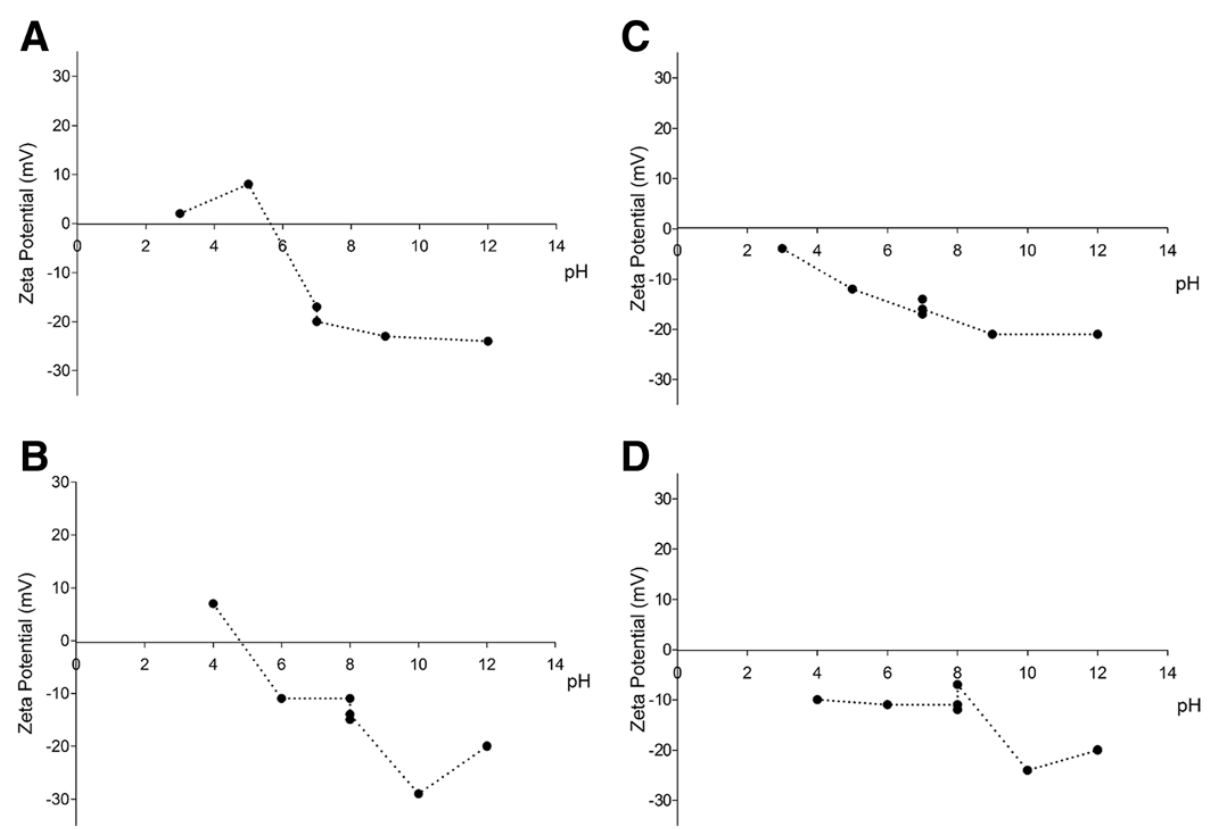

Figure 2 Behavior of Zeta Potential of Chlorella vulgaris exposed to nanoparticles. C. vulgaris exposed to Multi-walled carbon nanotubes (MWCNT) in Bold's basal (BB) culture medium (A) and Seine river water (B) at different pH. C. vulgaris exposed to cotton cellulose nanofibers (CNFs) in BB culture medium (C) or Seine river water (D) at different $\mathrm{pH}$. The ZP decreases with increasing $\mathrm{pH}$. Data are presented as mean from three independent experiments.

activity decreases $(0.673 \pm 0.03 ; \mathrm{P}=0.004)$ for the cells exposed to $100 \mu \mathrm{g} \mathrm{m}^{-1} \mathrm{MWCNs}$ after 24 hours exposure (Figure 5A). After 96 hours, for MWCNT nanoparticles, a decrease of the photosynthetic activity at all concentrations $(\mathrm{P}<0.05)$ was observed. For cotton CNFs the $\mathrm{Fv} / \mathrm{Fm}$ decrease was significant $(0.522 \pm 0.01 ; \mathrm{P}<0.001)$ for $1 \mu \mathrm{g} \mathrm{ml}{ }^{-1}$, only after 96 hours of exposure. On the other hand, the photosynthetic activity decreases with time after contact with 50 and $100 \mu \mathrm{g} \mathrm{ml}^{-1}$ concentrations $(\mathrm{P}<0.05$, Figure $5 \mathrm{~A})$.

In the case of Seine river water (Figure 5B) no photosynthetic activity variation was observed $(\mathrm{P}>0.05)$ after contact with $1 \mu \mathrm{g} \mathrm{ml}^{-1}$ MWCNT after 48 and 96 hours as well as after contact with $50 \mu \mathrm{g} \mathrm{ml}^{-1}$ after 24,48 and 96 hours and after contact with $100 \mu \mathrm{g} \mathrm{ml}^{-1}$ between 24 and 72 hours. However, for $1 \mu \mathrm{g} \mathrm{ml}^{-1}$ MWCNT after 24 hours $(0.805 \pm 0.05, \mathrm{P}=0.04), 50 \mu \mathrm{g} \mathrm{ml}^{-1}$ MWCNT after 72 hours $(0.791 \pm 0.05, \mathrm{P}<0.001)$ and $100 \mu \mathrm{g} \mathrm{ml}^{-1}$ after 96 hours $(0.458 \pm 0.03, \mathrm{P}<0.001)$, the photosynthetic activities decreased significantly. No changes occurred in cells exposed to $1 \mu \mathrm{g} \mathrm{ml}^{-1}$ cotton CNF after 24 hours and $50 \mu \mathrm{g} \mathrm{ml}^{-1}$ cotton CNFs after 96 hours $(\mathrm{P}>0.05)$. However, for all other conditions photosynthetic activity alteration was observed $(\mathrm{P}<0.05$; Figure $5 \mathrm{~B})$.

The present findings seem to be consistent with other studies which found that algal photosynthetic activity was also suppressed at nano- $\mathrm{Ag}$ [18], $\mathrm{ZnO}$ [19] and nano$\mathrm{TiO}_{2}$ [20]. However, Schwab et al. [10] demonstrated that the photosynthetic yield of C. vulgaris remained unchanged, even at concentrations up to $40 \mathrm{mg}$ pristine or oxidized CNT/L. This inconsistency may be due to the chemical functionalization of the CNT. In the current study, we used non-functionalized MWCNTs. Several studies have revealed that $\mathrm{CNT}$ surface functionalization may alter the toxicity response [21-23].

Gao et al. [24] found that nanomaterial toxicity after contact with photosynthetic organisms is also exhibited by reductions in the photochemical efficiency of the PSII. A decrease in the photosynthetic activity may be caused by a defect in the quantum yield of PSII itself, such as non-photochemical quenching [25]. It is possible, therefore, that long-term exposure or high concentrations of NPs affect the photosynthetic rate in C. vulgaris via alterations in the PSII photochemical efficiency. Further research should be done to investigate this. Microscopy analysis showed interaction between NPs and microalgae (Figure 4C-F). It can thus be suggested that the accumulation of NPs on the surface of C. vulgaris cell walls may inhibit photosynthetic activity because of shading effects, i.e., reduced light availability. In addition, the primary cause of the observed photosynthetic inhibition by NPs in green microalga could be an excessive level of ROS formation [25]. To further investigate this, we examined whether the MWCNTs and the cotton CNFs have cytotoxic impact by altering the intracellular oxidative status. 


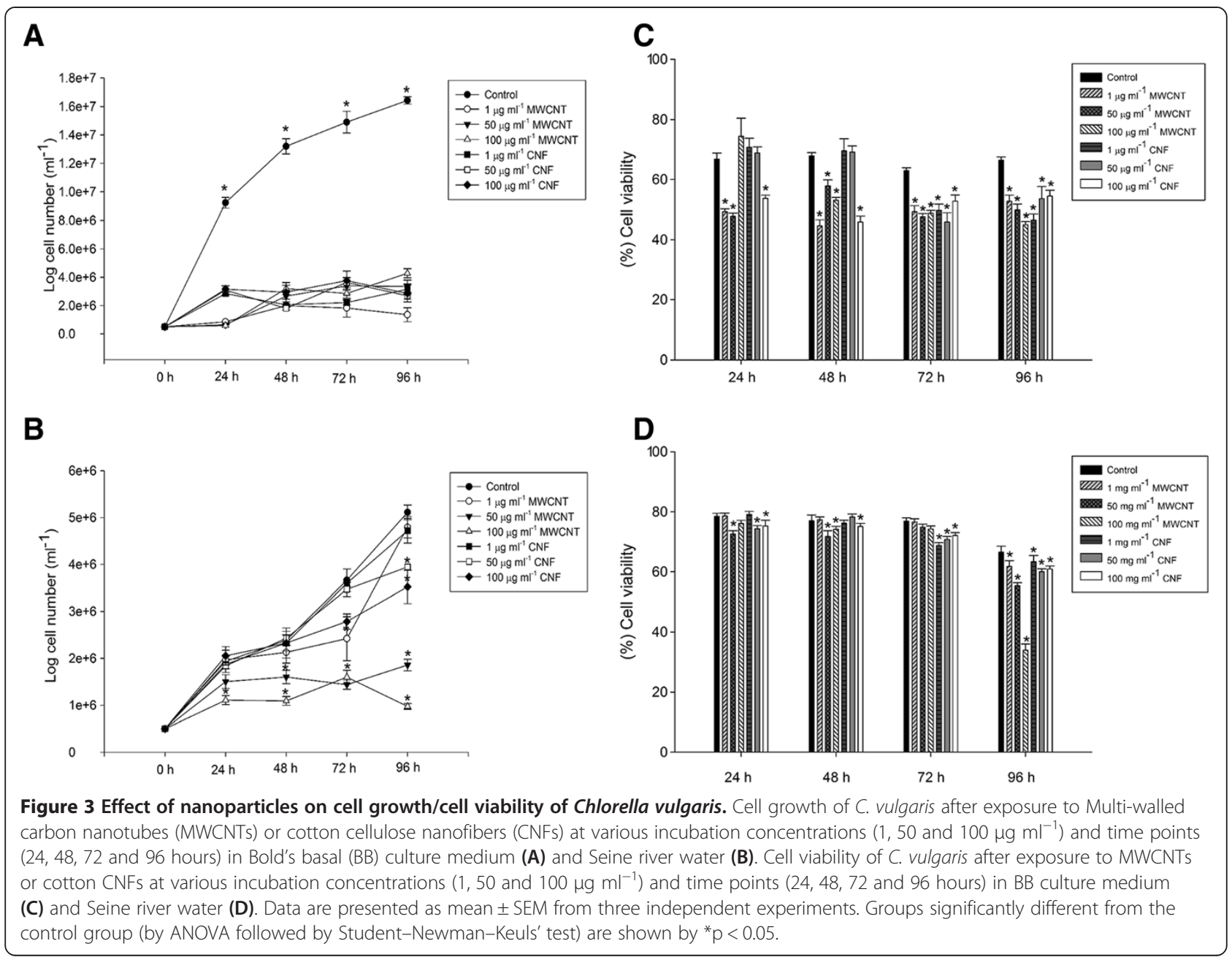

\section{Effect of NPs on SOD activity}

The activity of the antioxidant enzyme superoxide dismutase (SOD) was determined in C. vulgaris after exposure to NPs. SOD activity increased $(\mathrm{P}<0.05)$ in cells exposed to MWCNTs and cotton CNFs in BB culture medium and remained higher than the controls at all-times except for $100 \mu \mathrm{g} \mathrm{ml}^{-1}$ after 96 hours (see Additional file 1: Table S1). In Seine river water, an increase of SOD activity was observed after 24 hours $(\mathrm{P}<0.05$; see Additional file 1 : Table S1). These results are consistent with previous studies, which have shown that the CNT treatment can induce significant ROS production and influence cell viability [26-28]. Interestingly, no differences $(\mathrm{P}>0.05)$ were found in cells exposed to $50 \mu \mathrm{g} \mathrm{ml}^{-1}$ cotton CNF after 48, 72 and 96 hours and $100 \mu \mathrm{g} \mathrm{ml}^{-1}$ after both 48 and 96 hours (see Additional file 1: Table S1). In addition, no differences $(\mathrm{P}>0.05)$ were found between $50 \mu \mathrm{g} \mathrm{ml} \mathrm{m}^{-1}$ MWCNT and the control after 96 hours (see Additional file 1: Table S1).

Cheng et al. [29] showed that the ROS generation was involved in the activation of the mitochondria-dependent apoptotic pathway in cells exposed to CNTs. These findings further support the idea that nanoparticle-induced ROS production in cells can lead to cell death. In the present study, a decrease in cell viability was observed when algae cells were exposed to MWCNTs and cotton CNFs. On the other hand, Meng et al. [30] suggested that ROS were not widely generated by carboxylated MWCNTs incubation. As previously discussed, the functionalization of CNTs can alter their cellular interaction pathways. The potential impact of cotton CNFs on cell oxidative stress is little known. In a recent study, exposure to cotton CNFs resulted in an increase of oxidative stress response gene expression in mammalian fibroblast [17]. This finding corroborates the results in the present study, which showed oxidative stress on microalgae exposed to cotton CNFs (see Additional file 1: Table S1).

SOD is one of the most important antioxidative enzymes, which catalyzes the superoxide dismutation $\left(\mathrm{O}_{2}^{-}\right)$ into oxygen and hydrogen peroxide. It plays an important role in the protection of cells against ROS by lowering the steady state of superoxide anions. The increased 


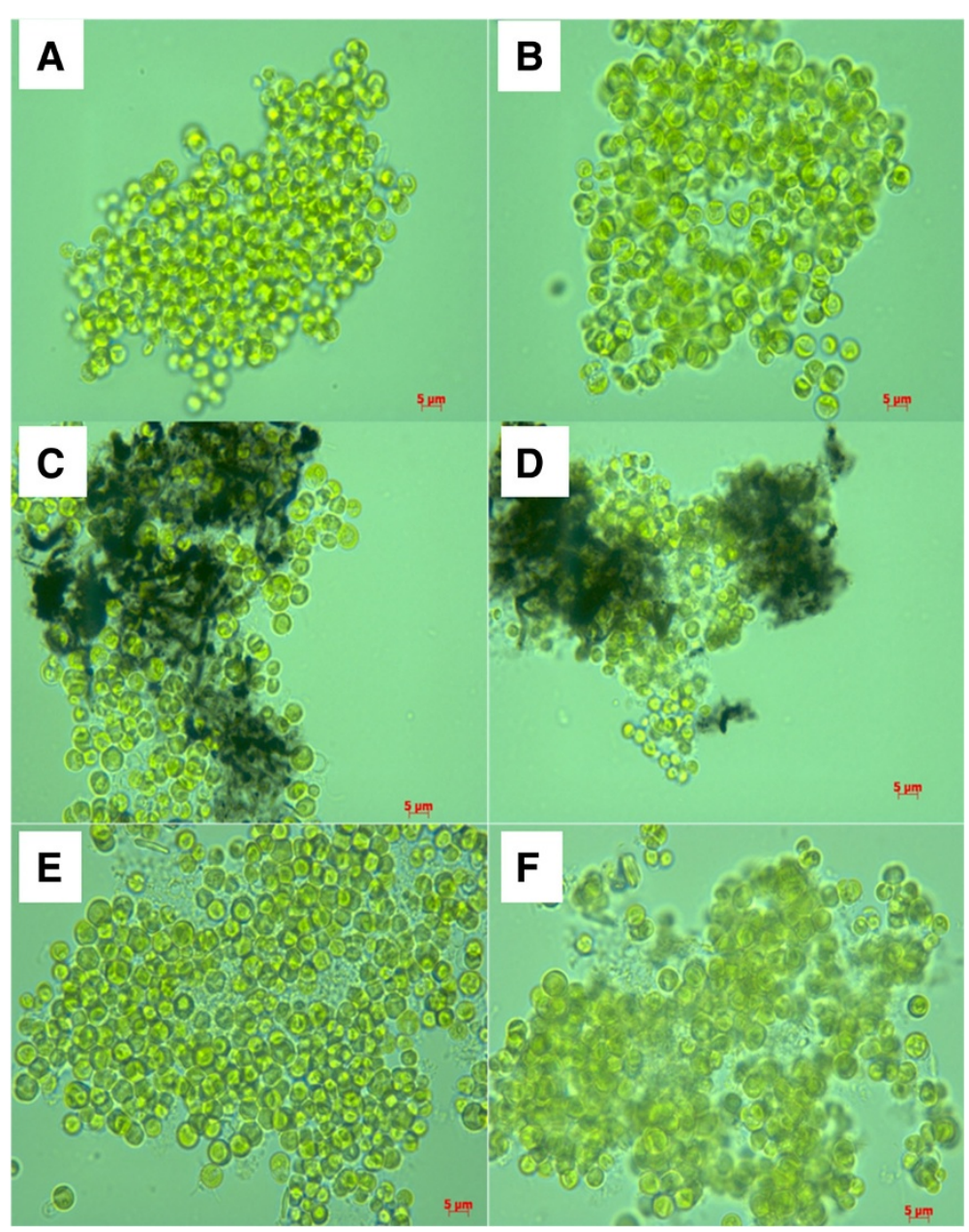

Figure 4 Optical micrographs of Chlorella vulgaris treated with different nanoparticles at $100 \mathbf{~ g ~ m l}^{-1}$ for $\mathbf{2 4}$ hours. Control Bold's basal (BB) culture medium (A), Control Seine river water (B), Multi-walled carbon nanotubes (MWCNT) in BB culture medium (C), MWCNT in Seine river water (D), cotton cellulose nanofibers (CNFs) in BB culture medium (E) and CNF in Seine river water (F). Note nanoparticle aggregates in C. vulgaris cells. Bars, 5 mm. Magnification $400 \times$.

activity of SOD in cells after contact with MWCNTs and cotton CNFs suggests a possible survival mechanism for C. vulgaris, in order to reduce possible cytotoxic effects such as cell death. However, data from cell viability showed that under some exposure conditions the cellular antioxidant system may not be able to prevent cell death induced by NPs. Thus, the production of ROS is one of the key factors contributing to the toxicity of nanomaterials in freshwater green microalgae.

In the Seine river water, only at $1 \mu \mathrm{g} \mathrm{ml}^{-1}$ MWCNT concentration after 96 hours, a decrease in SOD activity was observed, when compared to the control (see Additional file 1: Table S1). The exact cause of the decrease in SOD activity in cells exposed to $1 \mu \mathrm{g} \mathrm{ml}{ }^{-1}$ MWCNTs in Seine river water is not known. It has been suggested that the oxidative stress and the accumulation of hydrogen peroxide, which irreversibly inactivates SOD, might possibly disturb SOD synthesis by damaging the mitochondrial function [31]. Another possible explanation is that the impairment in the antioxidant defense system weakens ROS detoxification, which exacerbates cell death when such cells are exposed to an acute oxidative challenge [32]. Hence, it could be conceivably hypothesized that $C$. vulgaris, under certain culture conditions, may be more vulnerable to oxidative stress as a result of a greater oxidative burden, or, alternatively, lower antioxidant protection. Since the formation of ROS by MWCNTs and cotton CNFs is unclear, the mechanism of ROS formation by these NPs needs further investigation.

\section{Effect of NPs on ATP production in microalgae cells}

Since a cellular redox change may decrease the energy production in the form of ATP from mitochondria, we examined intracellular ATP levels. Figure 5 shows the decline in ATP levels in cells after exposure to NPs. The ATP levels after contact with both MWCNT and cotton 

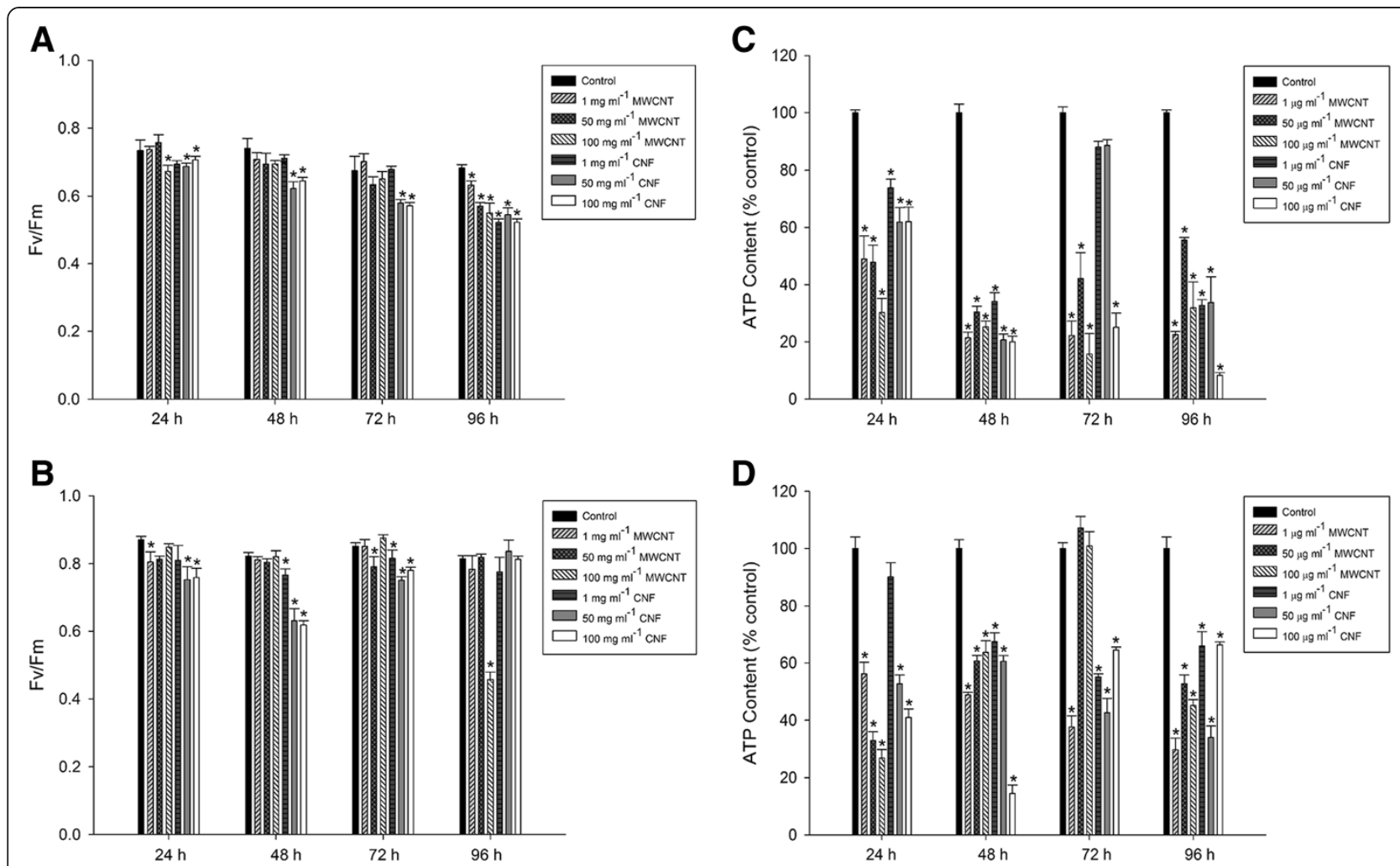

Figure 5 Influence of nanoparticles to activity of photosynthetic apparatus (Fv/Fm) and ATP levels of Chlorella vulgaris. Maximum quantum efficiency of the photosystem II (FV/Fm) of C. vulgaris cultured under different concentrations (1,50 and $\left.100 \mu \mathrm{m} \mathrm{ml}{ }^{-1}\right)$ of Multi-walled carbon nanotubes (MWCNTs) or cotton cellulose nanofibers (CNFs) at various time points (24, 48, 72 and 96 hours). Bold's basal (BB) culture medium (A) and Seine river water (B). ATP levels of C. vulgaris cells following at 24, 48, 72 and 96 hours coincubation with either MWCNTs or cotton CNFs $\left(1,50\right.$ or $\left.100 \mathrm{\mu g} \mathrm{mL}^{-1}\right)$ in BB culture medium (C) and Seine river water (D). Data are presented as mean \pm SEM from three independent experiments. Groups significantly different from the control group (by ANOVA followed by Student-Newman-Keuls' test) are shown by * $p<0.05$.

CNF decreased, and after 48 hours they were significantly lower than the levels in the control cells (Figure $5 \mathrm{C}$ and D). However, ATP levels were not changed $(\mathrm{P}>0.05)$ after 72 hours of exposure to 1 and $50 \mu \mathrm{g} \mathrm{ml}^{-1}$ cotton CNFs (BB culture medium) or after 24 hours of exposure to $1 \mu \mathrm{g} \mathrm{ml}^{-1}$ cotton CNF and after 72 to 50 and $100 \mu \mathrm{g} \mathrm{ml}^{-1}$ (in the Seine river water) (Figure $5 \mathrm{C}$ and $\mathrm{D}$ ). Little is known about the potential effects of NPs on mitochondria. Some studies showed that particle-ultra-fine carbon black and nanoscale zerovalent iron caused a decrease in ATP levels [33,34]. In addition, SWCNTs decrease mitochondrial membrane potential, inducing the formation of ROS on neuronal cells [35].

Mitochondria are responsible for an efficient coupling of cellular respiration to ATP production. Thus, mitochondrial dysfunction can contribute to cell death by reducing ATP production, increasing ROS production and releasing regulatory death [36]. Additionally, Fariss et al. [37] reported that ROS cause damage to the mitochondrial genome, impairing its activity. ATP is a universal energy unit in all living cells, and a decline in ATP levels is indicative of loss in mitochondrial function. In the current study, the variation of intracellular ATP levels after contact with MWCNT and cotton CNF particles compared to untreated cells, suggest that both MWCNTs and cotton CNFs impair the energetic metabolism of C. vulgaris.

\section{Microscopic study of microalgal cells exposed to NPs}

In order to further explore the cellular mechanisms of the observed NP toxicity, we used optical, SEM and TEM microscopies of the C. vulgaris cells exposed to MWCNTs and cotton CNFs in both BB culture medium and Seine river water. The optical microphotographs for $C$. vulgaris exposed to NPs at the highest concentration $\left(100 \mu \mathrm{g} \mathrm{ml}^{-1}\right)$ show the formation of particle aggregates on algal cells after 24 hours (Figure 4C-F). Figure 4C, D and F demonstrate that the majority of cells are completely trapped inside the shell of NPs. Under these circumstances, cells probably undergo stress due to the lack of essential nutrients and energy. To corroborate our results, it was suggested by Rodea-Palomes et al. [38] that the Anabaena cells trapped inside the nanoparticle shell, as well as the transport of nutrients and metabolites across the cell wall 
and membrane could be affected, leading to cell death. The aggregation of NPs depends on particle concentrations, $\mathrm{pH}$, zeta potential and the characteristics of the aqueous media [39]. It is well known that those particles with more positive $\mathrm{ZP}$ than $+30 \mathrm{mV}$ or more negative $\mathrm{ZP}$ than $-30 \mathrm{mV}$ are normally considered to be stable [23]. Thus, ZP is a critical parameter, which determines nanoparticle stability or aggregation in dispersion. In the present study, all absolute $\mathrm{ZP}$ values were lower than $30 \mathrm{mV}$ (Figure 2). Our results demonstrate that NPs in both BB culture medium and Seine river water are unstable solutions. This finding may be explained by the fact that both neutral $\mathrm{pH}$ in the cell medium ( $\mathrm{pH} 7.4)$ and the high ionic strength led to a higher degree of NP agglomeration [15]. In addition, an essential property governing the behavior of NP suspension in aqueous media is their tendency to form aggregates [38]. The affinity of microalgal cells to MWCNTs and cotton CNFs suggests that there must be a specific interaction between NPs and the $C$. vulgaris surface, strong enough to override the electrostatic repulsion of the negatively charged NPs and microalgae (observed in ZP, Figure 2).

Several factors govern the effect of NPs on microalgal growth, among them we can cite flocculation, light and nutrient availability [40]. A previous study revealed that growth inhibition was highly correlated with the shading of CNTs and the agglomeration of algal cells [7]. MWCNTs, at high concentrations, were shown to impair cell viability and this effect seems to be due to the strong tendency of CNTs to agglomerate [41]. In addition, Clément et al. [42] showed that aggregates reduce the fluorescence of algal cells, affecting toxicity. Therefore, the important problem encountered in the investigation of CNT toxicity is the tendency to aggregate [43]. Here, the results from Trypan blue exclusion assay and optical microscopy suggest that the formation of NP aggregates might alter the cellular acquisition of essential nutrients by cells and decrease cell viability.

In order to evaluate morphological, cellular ultrastructure changes and interaction between NPs and C. vulgaris, we analyzed microalgae cells by SEM and TEM after 48 hours of contact with MWCNT and cotton CNF $\left(100 \mu \mathrm{g} \mathrm{ml}^{-1}\right)$. In the control group (Figure 6A), the cell structure is intact, and the shape of the C. vulgaris appears round. However, cell shrinkage was noted on the cells treated with both MWCNTs and cotton CNFs (Figure 6B and E). Figure 6F shows gum-like cellulose surrounding the microalgae. Previous studies have shown that the interaction between NPs and phytoplankton produced EPS $[19,44]$. The increased production of EPS was found to be a general response to the presence of pollutants [45]. Brayner et al. [19] suggested that the polysaccharides produced by Anabaena flos-aquae avoid particle internalization. On the other hand, here the production of EPS in microalgae may have increased the adsorption of NPs on the cell surface. Cellulose is made of long sugar molecule chains. During

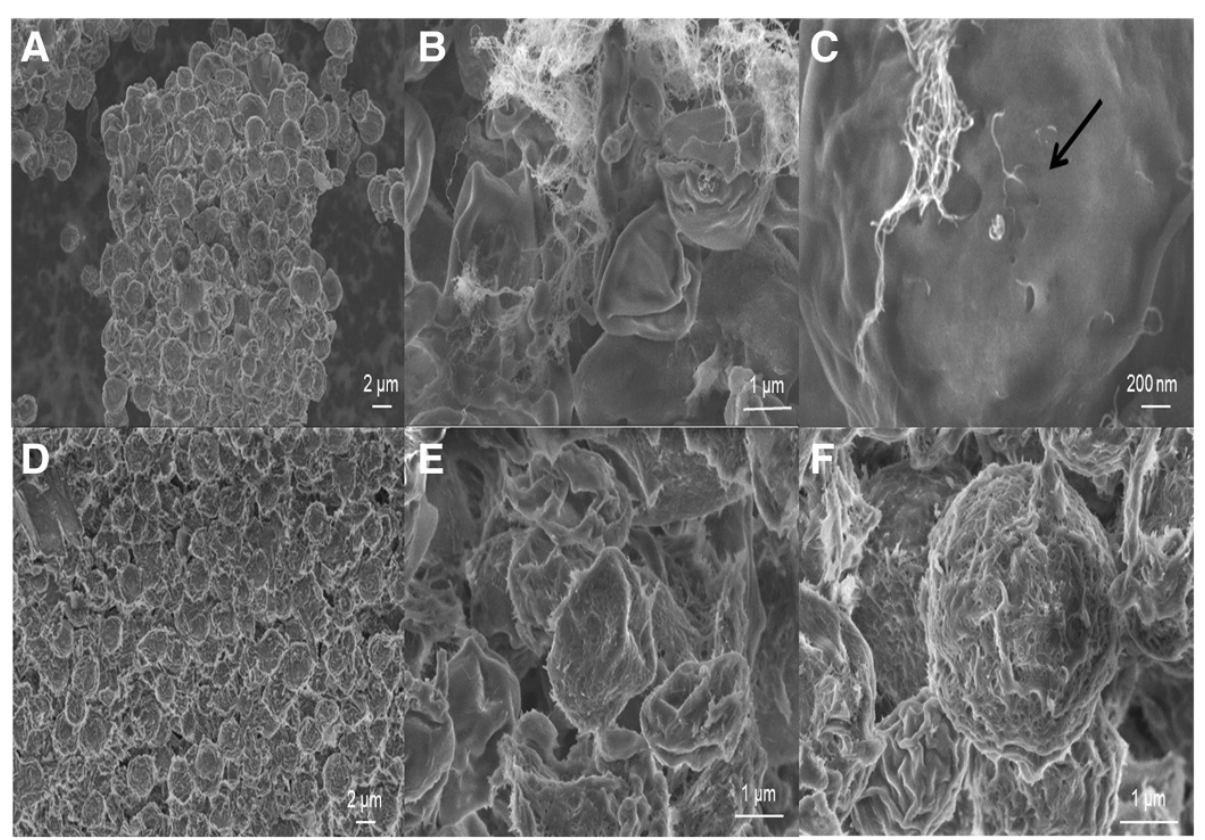

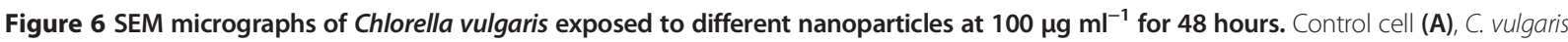
cells in close contact to Multi-walled carbon nanotubes aggregates (B-C), the black arrows indicate highly damaged cell (C). C. vulgaris cells coated with cotton cellulose nanofibers (D-F). Detail of highly damaged C. vulgaris cell (E). 
hydrolysis, such chains are broken down into simple sugars. In the present study, it is possible to hypothesize that cotton CNF chains have been broken down producing a glue gel-like water suspension. Therefore, a strong interaction between cotton CNFs and the EPS produced by $C$. vulgaris is possible. The adsorption of the NPs to the cell wall may impair gas exchange and transport nutrients across the plasma membrane. Thus, such cotton CNF adsorption surface is most probably the cause of the observed reduction in the photosynthetic activity (Figure 5A and B).

MWCNTs are commonly associated with the plasmatic membrane (Figure 6C), suggesting that CNTs could cross the cell wall and the plasma membrane and then enter into the cells. In fact, stained ultrathin sections from MWCNT-treated cells revealed the presence of CNTs in the cytoplasm (Figure 7B) while no evidence of CNFs was found inside the cells (Figure 7C). This result may be explained by the fact that the cellular uptake pathway of the NPs depends on the particle physico-chemical properties and the surface features. The aspect regarding high ratio, high stiffness and buckle flexing capabilities of MWCNT may have facilitated its crossing cellular barriers. $C$. vulgaris possesses cell walls which constitute a primary site for interaction and formation of a barrier against the entrance of NPs into their cells. In the present study, only free MWCNTs were introduced to the cells (Figure 7B). This finding corroborates the ideas of Wei et al. [46] who suggested that only NPs and NP aggregates with a smaller size are expected to pass through the cell walls and reach the plasma membranes.

Interestingly, cells in Seine River water did not show internalization of MWCNTs (Figure 7E). A possible explanation for this might be that the culture system type (BB culture medium or the River seine water) affects cellular uptake of MWCNTs in C. vulgaris cells. Recently, in vitro studies have shown that the culture medium composition may affect the proteins that are expressed on the cytoplasmic membrane, which may influence the internalization of MWCNTs [47]. In addition, in Seine River water, the interactions of natural polymers with MWCNT may prevent the internalization of this NP into C. vulgaris cells. Further research should be done to investigate the cellular uptake of MWCNTs in microalgae cells in different medium composition.

The observed adsorption of both MWCNTs and cotton CNFs to the cell surface may result in the disruption of the cell wall and membrane. Such loss in cell membrane integrity may lead to cell death. TEM images of microalgae exposed to MWCNTs both in BB culture medium and in Seine river water show damage to cell membranes (Figure $7 \mathrm{~B}$ and $\mathrm{E}$ ). The micrograph shows a

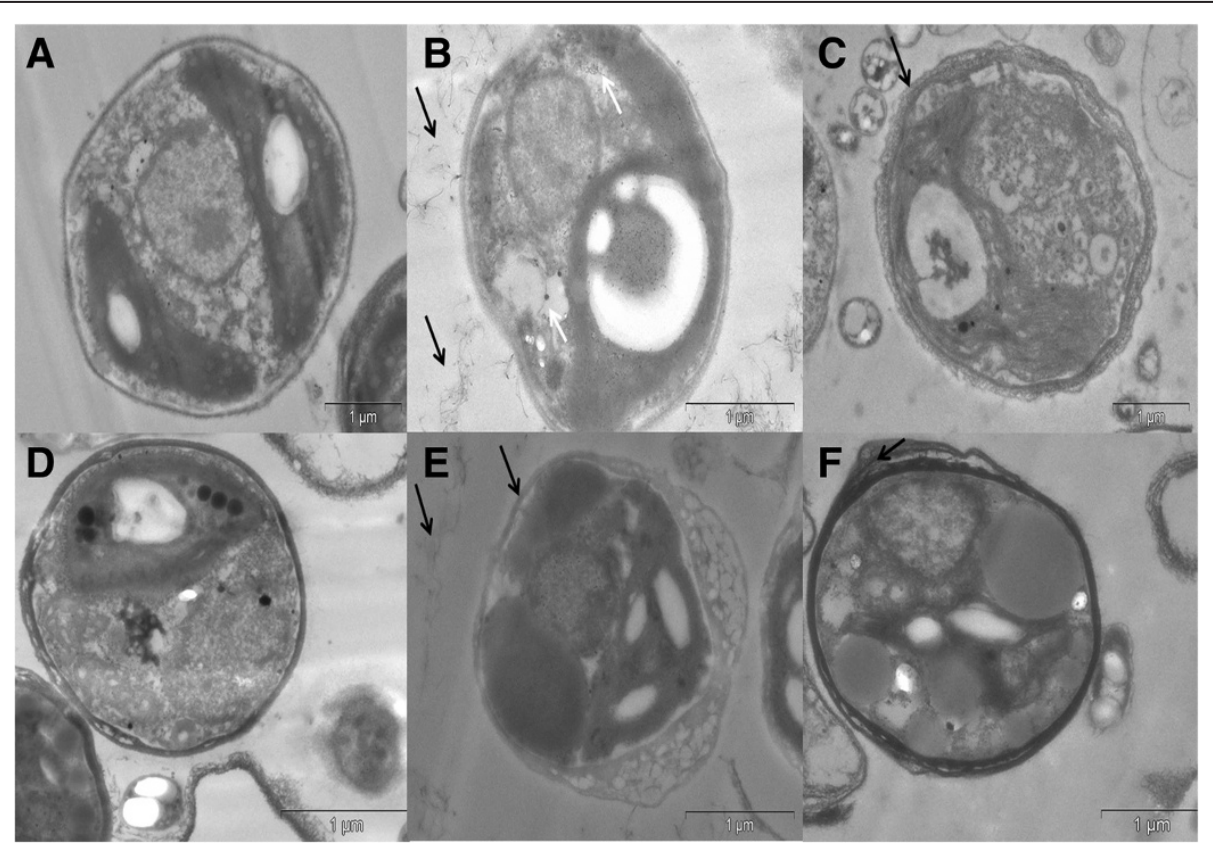

Figure 7 TEM results of Chlorella vulgaris exposed to different nanoparticles at $100 \mu \mathrm{g} \mathrm{ml}^{-1}$ for $\mathbf{4 8}$ hours. C. vulgaris cell cultured with Bold's basal (BB) culture medium only (A), C. vulgaris cell cultured with Multi-walled carbon nanotubes (MWCNTs) in BB culture medium (B), C. vulgaris cell cultured with cotton cellulose nanofibers (CNFs) in BB culture medium (C); C. vulgaris cell cultured with Seine river water only (D), C. vulgaris cell cultured with MWCNT in Seine river water (E), C. vulgaris cell cultured with cotton CNFs in Seine river water (F). MWCNTs (small black tubes) are inside the cell (B) while there is no evidence of cotton CNFs was found inside the cells. Black arrows: extracellular MWCNTs or cotton CNF; white arrows: intracellular MWCNTs. 
cell, which has partly lost its cell wall and membrane. It is therefore likely that membrane damages lead to the release of cytoplasmic elements. Only dead cells, with disrupted plasma membrane, will be labelled by Trypan blue dyes. Thus, in this study, data from Trypan blue assay corroborate the microscopy findings.

It is not clear whether the internalization of particles is relevant to the induction of intracellular effects or the toxicity may be due to the adsorption of NPs on the cellular membrane [38]. In the present study, two hypotheses are possible: cotton CNFs anchor to the algal cell surface and internalization of the MWCNTs induces membrane rupture, morphologic alterations and toxic effects.

\section{Conclusions}

Under the conditions tested, such results confirmed that exposure to MWCNTs and to cotton CNFs affects cell viability and algal growth. The toxicity of NPs on $C$. vulgaris has several causes. NPs appear to affect algae growth and cause cell death by inducing oxidation, disturbing ATP production, decreasing photosynthetic activity and physical stress. Cellular uptake of MWCNTs was observed in algae cells cultured in BB culture medium, but cells cultured in Seine river water did not internalize MWCNTs. Together, such factors might have contributed to the decline in culture algae exposed to NPs.

\section{Methods}

\section{Preparation and dispersion of nanoparticles}

The MWCNTs (diameters of about 20-40 nm and lengths of $40-60 \mu \mathrm{m}$ ) were synthesized by means of a floating catalytic chemical vapor deposition process using ferrocene and ethylene as the transition metal and carbon precursors, respectively. After synthesis, the MWCNTs were submitted to a simple purification process, by means of which they were washed and filtered several times with isopropyl alcohol in a Millipore filtration system, in order to remove any non-reacted ferrocene and other carbon impurities. After the cleaning process, the MWCNTs were dried at $80^{\circ} \mathrm{C}$ for 12 hours. The CNFs (diameters of about 6-18 $\mathrm{nm}$ and lengths of $85-225 \mu \mathrm{m}$ ) were prepared from $5 \mathrm{~g}$ of cotton fibers which were dispersed in $100 \mathrm{ml}$ of $6.5 \mathrm{M}$ sulfuric acid at $45^{\circ} \mathrm{C}$ and vigorously stirred for 75 minutes. After that, $500 \mathrm{ml}$ of cold distilled water was added to stop the reaction. The sulfuric acid was partially removed from the resulting suspension by centrifugation at $8,000 \times \mathrm{g}$ for 15 minutes. The non-reactive sulfate groups were removed by centrifugation followed by dialysis. Then, the fibers were resuspended and dialyzed against tap water with a tubing cellulose membrane $(76 \mathrm{~mm}$, D9402-Sigma) until the $\mathrm{pH}$ reached 6-7. The resulting suspension was sonicated (Branson 450 sonifier, Branson Ultrasonics, Danbury, USA) for 5 minutes (in ice bath) and stored in a refrigerator. Stock solutions of the nanomaterials $\left(10 \mathrm{mg} \mathrm{ml}^{-1}\right)$ were prepared in BB culture medium or water from the Seine river, filtered by sonication in an ultrasonic bath during 20 minutes at $20 \mathrm{~W}$.

\section{$X$-ray diffraction (XRD)}

XRD patterns were recorded using an X'Pert PRO (PAN alytical) diffractometer with Co K $\alpha$ radiation. The diffractometer was calibrated using a standard Si sample. The samples were placed on a Si holder (absence of Si peaks).

\section{Zeta potential (ZP)}

Zeta potential of NPs in BB culture medium or filtered Seine river water $(0.22 \mu \mathrm{m})$ was determined using a Malvern zetasizer Nano ZS, at the same experimental conditions as used for the growth test. Three replicates per treatment were measured at $0,24,48,72$, and 96 hours. NP suspensions with and without algae, at different pHs, were compared. The zeta potential was plotted $v s . \mathrm{pH}$ and the value where the zeta potential equaled zero was taken to be the PZC.

\section{Scanning electron microscopy (SEM)}

The samples were imaged by a Zeiss Supra 40 scanning electron microscope equipped with an in-lens detector. For imaging, low excitation voltage $(2.5 \mathrm{kV})$ and a small working distance $(6 \mathrm{~mm})$ were used. Under these experimental conditions, charging effects were minimal, and therefore, it was not necessary to metalize the samples, so that true sample features were not masked.

\section{Culture conditions}

C. vulgaris was grown in a $250 \mathrm{ml}$ Erlenmeyer flask, with $0.22 \mu \mathrm{m}$ vented plug seal cap, in sterile BB culture medium at $\mathrm{pH} 7.4$ (adjusted with $1 \mathrm{M} \mathrm{NaOH}$ solution) or in Seine river water sterilized by $0.22 \mu \mathrm{m}$ filtration at a controlled temperature of $20.0 \pm 0.5^{\circ} \mathrm{C}$ and luminosity of $50-80 \mu \mathrm{mol} \mathrm{m} \mathrm{m}^{-2} \mathrm{~s}^{-1}$ photosynthetic photon flux. Appropriate concentrations of each nanomaterial stock solution were added to a microalgal culture in the exponential growth phase and incubated for 24, 48, 72 and 96 hours.

\section{Viability assay}

The Cellometer Auto X4 simultaneously calculates cell concentration and \% viability for cultured cells stained with Trypan blue. Trypan blue is a vital stain used to selectively color dead tissues or cells blue. It is a diazo dye. Live cells or tissues with intact cell membranes are not colored. Since cells are very selective in the compounds that pass through the membrane, in a viable cell, Trypan blue is not absorbed; however, it traverses the membrane in a dead cell. Hence, dead cells are shown as a distinctive blue color under a photonic microscope. 


\section{PSII fluorescence measurements}

The photosynthetic activity of microalgae was measured using the PAM method with a Handy PEA (Hansatech instruments) fluorometer. This method uses the saturation pulse method, in which a phytoplankton sample is subjected to a short beam of light that saturates the PSII reaction centers of the active chlorophyll molecules. This process suppresses photochemical quenching, which might otherwise reduce the maximum fluorescence yield. A ratio of variable-over-maximal fluorescence $(\mathrm{Fv} / \mathrm{Fm})$ can then be calculated which approximates the potential quantum yield of PSII.

\section{Superoxide dismutase (SOD) assay}

The SOD activity was spectrophotometrically determined using the SOD kit (19160) purchased from Sigma-Aldrich (Chemie $\mathrm{GmbH}$, Germany), following the instructions in the kit. After incubating the plate at $37^{\circ} \mathrm{C}$ for 20 minutes, absorbance was read at $450 \mathrm{~nm}$ using a microplate reader.

\section{ATP content bioluminescent assay}

Intracellular levels of ATP were quantified with the ATP bioluminescent assay (Sigma) according to the manufacturer's recommendations. Relative luminescent units were detected with an Envision Multilabel Plate Reader (PerkinElmer, Massachusetts, MA, USA).

\section{Optical microscopy}

Interaction of NPs with C. vulgaris cells was studied by optical microscopy (Zeiss Primo Star microscope) after 24 hours of exposure to MWCNTs or cotton CNFs $\left(100 \mu \mathrm{g} \mathrm{ml}^{-1}\right)$.

\section{Transmission electron microscopy (TEM) and scanning electron microscopy (SEM)}

After 48 hours exposure to MWCNTs or cotton CNFs $\left(100 \mu \mathrm{g} \mathrm{ml}^{-1}\right)$, the microalgae were fixed with a mixture containing $2.5 \%$ glutaraldehyde, $0.5 \%$ osmium tetroxide and $1.0 \%$ picric acid in a phosphate Sörengen buffer $(0.1 \mathrm{M}$, $\mathrm{pH}$ 7.4). Dehydration was then achieved in a series of ethanol baths, and the samples were processed for embedding in a Spurr resin. Ultrathin sections were made using a Reichert-Young Ultracut microtome (Leica). Sections were contrasted with a $4 \%$ aqueous uranyl acetate solution and Reynold's lead citrate before visualization. TEM imaging was performed with a Tecnai 12 operating at $80 \mathrm{kV}$ equipped with a $1 \mathrm{~K} \times 1 \mathrm{~K}$ Keen View camera. For SEM, the samples were dried with a supercritical point dryer after ethanol baths.

\section{Statistical analysis}

Data were analyzed by ANOVA and differences among means were compared by the Student-Newman-Keuls' test using the general linear model by SAS version 9.1
(SAS Institute, Cary, NC, USA). Differences between different groups were considered statistically significant at $\mathrm{P}<0.05$. The results were presented as arithmetic mean \pm standard error of mean (SEM).

\section{Additional file}

Additional file 1: Table S1. Superoxide dismutase activity in Chlorella vulgaris exposed to Multi-walled carbon nanotubes (MWCNTs) or cotton cellulose nanofibers (CNFs) at different time points.

\section{Abbreviations}

ATP: Adenosine triphosphate; BB: Bold's basal medium; CNF: Cellulose nanofibers; CNT: Carbon nanotube; EPS: Extracellular polymeric substance; Fv/Fm: Variable over maximal fluorescence; MWCNT: Multi-walled carbon nanotubes; NP: Nanoparticle; PAM: Pulsed amplitude modulation; PSII: Photosystem II; PZC: Potential of zero charge; ROS: Reactive oxygen species; SEM: Scanning Electron Microscopy; SOD: Superoxide dismutase; SWCNT: Single-walled carbon nanotube; TEM: Transmission Electron

Microscopy; XDR: X-ray diffraction; ZP: Zeta potential.

\section{Competing interests}

The authors declare that they have no competing interests.

\section{Authors' contributions}

The work presented here was carried out in collaboration between all authors. CY, AC, NRBR, HMB and RB planned and supervised the series of experiments. MMP carried out the laboratory experiments and analyzed the data. MMP, NRBR and RB interpreted the results and wrote the paper. LM and $J$ performed the electronic microscopic analysis. JMM and LOL produced and characterized the nanoparticles. All of the authors approved the manuscript.

\section{Acknowledgements}

This work was financially supported by Brazilian National Council for Scientific and Technological Development (236975/2012-9); Foundation for Research Support of Minas Gerais State (APQ04334-10); Coordination for the Improvement of Higher Education Personnel (04CII-2008/Projet 7 Network Brazil Nanobiotec). The authors are grateful to The National Collaborative Research Network in Nanotechnology Applied to Agribusiness (AGRONANO), Research Network in Nanobiotechnology of the State of Minas Gerais (NANOBIOMG).

\section{Author details}

${ }^{1}$ Nucleus of Analytical Identification and Quantification (NIQUA), Federal University of Juiz de Fora, 36036-900 Juiz de Fora, Brazil. ${ }^{2}$ Interfaces, Traitements, Organisation et Dynamique des Systèmes (ITODYS), University of Paris Diderot, Sorbonne Paris Cité, 7086 Paris, France. ${ }^{3}$ Muséum National d'Histoire Naturelle, Département Régulations, Développement et Diversité Moléculaire (RDDM), 75005 Paris, France. ${ }^{4}$ Institut Jacques Monod, CNRS, University Paris Diderot, 75205 Paris, France. ${ }^{5}$ Embrapa Instrumentation (CNPDIA), National Nanotechnology Laboratory for Agriculture (LNNA), 13560-970 São Carlos, Brazil. 'Department of Physics, Federal University of Minas Gerais, 31270-901 Belo Horizonte, Brazil. " Embrapa Dairy Cattle (CNPGL), 36038-330 Juiz de Fora, Brazil.

Received: 26 February 2014 Accepted: 14 April 2014 Published: 22 April 2014

\section{References}

1. Pan L, Pei X, He R, Wan Q, Wang J: Multiwall carbon nanotubes/ polycaprolactone composites for bone tissue engineering application. Colloids Surf B: Biointerfaces 2012, 93:226-234.

2. Ma S, Liu C, Yang K, Lin D: Coagulation removal of humic acid-stabilized carbon nanotubes from water by $\mathrm{PACl}$ : influences of hydraulic condition and water chemistry. Sci Total Environ 2012, 439:123-128. 
3. Chen YS, Hsiue GH: Directing neural differentiation of mesenchymal stem cellsby carboxylated multiwalled carbon nanotubes. Biomaterials 2013, 34(21):4936-4944.

4. De Volder MF, Tawfick SH, Baughman RH, Hart AJ: Carbon nanotubes: present and future commercial applications. Science 2013, 339(6119):535-539.

5. Kwok KWH, Leung KMY, Flahaut E, Cheng JP, Cheng SH: Chronic toxicity of double-walled carbon nanotubes to three marine organisms: influence of different dispersion methods. Nanomedicine 2010, 5:951-961.

6. Wei L, Thakkar M, Chen Y, Ntim SA, Mitra S, Zhang X: Cytotoxicity effects of water dispersible oxidized multiwalled carbon nanotubes on marine alga, Dunaliella tertiolecta. Aquat Toxicol 2010, 100:194-201.

7. Schwab F, Bucheli TD, Lukhele LP, Magrez A, Nowack B, Sigg L, Knauer K Are carbon nanotube effects on green algae caused by shading and agglomeration? Environ Sci Technol 2011, 45:6136-6144.

8. Lima R, Feitosa LO, Maruyama CR, Barga MA, Yamawaki PC, Vieira IJ, Teixeira EM, Correa AC, Mattoso LHC, Fraceto LF: Evaluation of the genotoxicity of cellulose nanofibers. Int J Nanomed 2012, 7:3555-3565.

9. Wilhelm C, Billotey C, Roger J, Pons JN, Bacri JC, Gazeau F: Intracellular uptake of anionic superparamagnetic nanoparticles as a function of their surface coating. Biomaterials 2003, 24:1001-1011.

10. Patil S, Sandberg A, Heckert E, Self W, Seal S: Protein adsorption and cellular uptake of cerium oxide nanoparticles as a function of zeta potential. Biomaterials 2007, 28:4600-4607.

11. Blaise C, Gagne F, Ferard JF, Eullaffroy P: Ecotoxicity of selected nanomaterials to aquatic organisms. Environ Toxicol 2008, 23:591-598.

12. Heister E, Lamprecht C, Neves V, Tîlmaciu C, Datas L, Flahaut E, Soula B, Hinterdorfer P, Coley HM, Silva SR, McFadden J: Higher dispersion efficacy of functionalized carbon nanotubes inchemical and biological environments. ACS Nano 2010, 4:2615-2626.

13. Rogers NJ, Franklin NM, Apte SC, Batley GE, Angel BM, Lead JR, Baalousha M: Physico-chemical behaviour and algal toxicity of nanoparticulate $\mathrm{CeO}_{2}$ in freshwater. Environ Chem 2010, 7:50-60.

14. Sargent LM, Shvedova AA, Hubbs AF, Salisbury JL, Benkovic SA, Kashon ML, Lowry DT, Murray AR, Kisin ER, Friend S, McKinstry KT, Battelli L, Reynolds SH: Induction of aneuploidy by single-walled carbon nanotubes. Environ $\mathrm{Mol}$ Mutagen 2009, 50(8):708-717.

15. Simon-Deckers A, Loo S, Mayne-L'hermite M, Herlin-Boime N, Menguy N, Reynaud C, Gouget B, Carrière M: Size-, composition- and shapedependent toxicological impact of metal oxide nanoparticles and carbon nanotubes toward bacteria. Environ Sci Technol 2009, 43:8423-8429.

16. Clift MJ, Foster EJ, Vanhecke D, Studer D, Wick P, Gehr P, Rothen-Rutishauser B, Weder $C$ : Investigating the interaction of cellulose nanofibers derived from cotton with a sophisticated 3D human lung cell coculture. Biomacromolecules 2011, 12:3666-3673.

17. Pereira MM, Raposo NR, Brayner R, Teixeira EM, Oliveira V, Quintão CCR, Camargo LS, Mattoso LH, Brandão HM: Cytotoxicity and expression of genes involved in the cellular stress response and apoptosis in mammalian fibroblast exposed to cotton cellulose nanofibers. Nanotechnology 2013, 24:075103.

18. Miao AJ, Schwehr KA, Xu C, Zhang SJ, Luo Z, Quigg A, Santschi PH: The algal toxicity of silver engineered nanoparticles and detoxification by exopolymeric substances. Environ Pollut 2009, 157:3034-3041.

19. Brayner R, Dahoumane SA, Yéprémian C, Djediat C, Meyer M, Couté A, Fiévet F: ZnO nanoparticles: Synthesis, characterization, and ecotoxicological studies. Langmuir 2010, 26:6522-6528.

20. Chen L, Zhou L, Liu Y, Deng S, Wu H, Wang G: Toxicological effects of nanometer titanium dioxide (nano-TiO2) on Chlamydomonas reinhardtii. Ecotoxicol Environ Saf 2012, 84:155-162.

21. Sayes CM, Liang F, Hudson JL, Mendez J, Guo W, Beach JM, Moore VC, Doyle CD, West JL, Billups WE, Ausman KD, Colvin VL: Functionalization density dependence of single-walled carbon nanotubes cytotoxicity in vitro. Toxicol Lett 2006, 161:135-142.

22. Vardharajula S, Ali SZ, Tiwari PM, Eroğlu E, Vig K, Dennis VA, Singh SR: Functionalized carbon nanotubes: Biomedical applications. Int $J$ Nanomedicine 2012, 7:5361-5374.

23. Jiang $Y$, Zhang $H$, Wang $Y$, Chen M, Ye S, Hou Z, Ren L: Modulation of apoptotic pathways of macrophages by surface-functionalized multi-walled carbon nanotubes. PLoS One 2013, 8:65756.

24. Gao J, Xu G, Qian H, Liu P, Zhao P, Hu Y: Effects of nano- $\mathrm{TiO}_{2}$ on photosynthetic characteristics of Ulmus elongata seedlings. Environ Pollut 2013, 176:63-70.
25. Rodea-Palomares I, Gonzalo S, Santiago-Morales J, Leganés F, García-Calvo E, Rosal R, Fernández-Piñas F: An insight into the mechanisms of nanoceria toxicity in aquatic photosynthetic organisms. Aquat Toxicol 2012, 122-123:133-143.

26. Manna SK, Sarkar S, Barr J, Wise K, Barrera EV, Jejelowo O, Rice-Ficht AC, Ramesh GT: Single-walled carbon nanotube induces oxidative stress and activates nuclear transcription factor-kappaB in human keratinocytes. Nano Lett 2005, 5:1676-1684.

27. Ye SF, Wu YH, Hou ZQ, Zhang QQ: ROS and NF-kappaB are involved in upregulation of IL-8 in A549 cells exposed to multi-walled carbon nanotubes. Biochem Biophys Res Commun 2009, 379:643-648.

28. Di Giorgio ML, Di Bucchianico S, Ragnelli AM, Aimola P, Santucci S, Poma A: Effects of single and multi walled carbon nanotubes on macrophages: cyto and genotoxicity and electron microscopy. Mutat Res 2011, 722:20-31.

29. Cheng WW, Lin ZQ, Wei BF, Zeng Q, Han B, Wei CX, Fan XJ, Hu CL, Liu LH, Huang $J H$, Yang $X, X i Z G$ : Single-walled carbon nanotube induction of rat aortic endothelial cell apoptosis: reactive oxygen species are involved in the mitochondrial pathway. Int J Biochem Cell Biol 2011, 43:564-572

30. Meng L, Chen R, Wang LM, Wang P, Li CZ, Bai R, Zhao YL, Autrup H, Chen C: Short multiwall carbon nanotubes promote neuronal differentiation of PC12 cells via up-regulation of the neurotrophin signaling pathway. Small 2013, 9:1786-1798.

31. Zupan G, Vitezić D, Mrsić J, Matesić D, Simonić A: Effects of nimodipine, felodipine and amlodipine on electroconvulsive shock-induced amnesia in the rat. Eur J Pharmacol 1996, 310:103-106.

32. Chirino $Y$ I, Sánchez-Pérez $Y$, Osornio-Vargas AR, Morales-Bárcenas $R$, Gutiérrez-Ruíz MC, Segura-García Y, Rosas I, Pedraza-Chaverri J, García-Cuellar CM: PM(10) impairs the antioxidant defense system and exacerbates oxidative stress driven cell death. Toxicol Lett 2010, 193:209-216.

33. Wilson MR, Lightbody JH, Donaldson K, Sales J, Stone V: Effects of silica nanoparticles on growth and photosynthetic pigment contents of Scenedesmus obliquus. Toxicol Appl Pharmacol 2002, 184:172-179.

34. Phenrat T, Long TC, Lowry GV, Veronesi B: Partial oxidation ("aging") and surface modification decrease the toxicity of nanosized zerovalent iron. Environ Sci Technol 2009, 43:195-200.

35. Wang J, Sun P, Bao Y, Liu J, An L: Cytotoxicity of single-walled carbon nanotubes on PC12 cells. Toxicol In Vitro 2011, 25:242-250.

36. Christophe M, Nicolas S: Mitochondria: a target for neuroprotective interventions in cerebral ischemia-reperfusion. Curr Pharm Des 2006 12:739-757.

37. Fariss MW, Chan CB, Patel M, Van Houten B, Orrenius S: Role of mitochondria in toxic oxidative stress. Mol Interv 2005, 5:94-111.

38. Rodea-Palomares I, Boltes K, Fernández-Piñas F, Leganés F, García-Calvo E, Santiago J, Rosal R: Physicochemical characterization and ecotoxicological assessment of $\mathrm{CeO} 2$ nanoparticles using two aquatic microorganisms. Toxicol Sci 2011, 119:135-145.

39. Keller AA, Wang H, Zhou D, Lenihan HS, Cherr G, Cardinale BJ, Miller R, Ji Z Stability and aggregation of metal oxide nanoparticles in natural aqueous matrices. Environ Sci Technol 2010, 44:1962-1967.

40. Metzler DM, Erdem A, Tseng YH, Huang CP: Responses of Algal Cells to Engineered Nanoparticles Measured as Algal Cell Population, Chlorophyll a, and Lipid Peroxidation: Effect of Particle Size and Type. J Nanotechnol 2012, 2012:237284

41. Davoren M, Herzog E, Casey A, Cottineau B, Chambers G, Byrne HJ, Lyng FM: In vitro toxicity evaluation of single walled carbon nanotubes on human A549 lung cells. Toxicol In Vitro 2007, 21:438-448.

42. Clément L, Zenerino A, Hurel C, Amigoni S, de Givenchy Taffin E, Guittard F, Marmier N: Toxicity assessment of silica nanoparticles, functionalised silica nanoparticles, and HASE-grafted silica nanoparticles. Sci Total Environ 2013, 450-451:120-128.

43. Smart SK, Cassady Al, Lu GQ, Martin DJ: The biocompatibility of carbon nanotubes. Carbon 2006, 44:1034-1047.

44. Chen SSC, Anaya JM, Zhang S, Spurgin J, Chuang CY, Xu C, Miao AJ, Chen EY, Schwehr KA, Jiang Y: Effects of engineered nanoparticles on the assembly of exopolymeric substances from phytoplankton. PLoS One 2011, 6:e21865.

45. Pistocchi R, Mormile MA, Guerrini F, Isani G, Boni L: Increased production of extra- and intracellular metal-ligands in phytoplankton exposed to copper and cadmium. J Appl Phycol 2000, 12:469-477. 
46. Wei CX, Zhang YB, Guo J, Han B, Yang X, Yuan JL: Effects of silica nanoparticles on growth and photosynthetic pigment contents of Scenedesmus obliquus. J Environ Sci 2010, 22:155-160.

47. Haniu H, Saito N, Matsuda Y, Tsukahara T, Maruyama K, Usui Y, Aoki K, Takanashi S, Kobayashi S, Nomura H, Okamoto M, Shimizu M, Kato H: Culture medium type affects endocytosis of multi-walled carbon nanotubes in BEAS-2B cells and subsequent biological response. Toxicol In Vitro 2013, 27:1679-1685.

doi:10.1186/1477-3155-12-15

Cite this article as: Pereira et al:: Ecotoxicological effects of carbon nanotubes and cellulose nanofibers in Chlorella vulgaris. Journal of Nanobiotechnology 2014 12:15.

\section{Submit your next manuscript to BioMed Central and take full advantage of:}

- Convenient online submission

- Thorough peer review

- No space constraints or color figure charges

- Immediate publication on acceptance

- Inclusion in PubMed, CAS, Scopus and Google Scholar

- Research which is freely available for redistribution 